\title{
Reflections on College Fine Arts Education in China
}

\author{
Fei Liu \\ Shandong Normal University \\ College of Fine Arts \\ Jinan, China \\ e-mail: 1140053235@qq.com
}

\begin{abstract}
In this age of information explosion, diversification seems to be the only choice one can make when faced with such a complicated world. Against this background, it seems hard for college fine arts education in China to keep abreast with the times due to its particularity of development. This paper intends to offer a few suggestions on the reform of China's college fine arts education through the analysis of its history of development, its current situation, and the overall environment of contemporary art.
\end{abstract}

Keywords-higher education in China; fine arts; Soviet Teaching Model; innovation; reform

\section{INTRODUCTION}

With internationalization and diversification of economic and cultural development and exchanges, it has become a public consensus that "any circumstance hitting a limit will begin to change; change will in turn lead to an unimpeded state, and then lead to continuity." As an integral part of higher education, fine arts education is also seeking the "law of change." As the road of change is long and tortuous, fine arts educators must base their plan of change on a good understanding of the current situation.

\section{CURRENT SITUATION}

To reform college fine arts education in China, the first thing to do is analyze the status quo, the source of the current teaching model and the weaknesses of such a model, then figure out solutions.

\section{A. Prevalence of the Soviet Teaching Model}

The Soviet Teaching Model adopted early on in China's college fine arts education has been followed to date. Realistic painting, which is characteristic of academics, is still prevalent.

When it comes to college fine arts education in China, the Soviet Teaching Model is an unavoidable term because it has been the standard fine arts education model adopted in Chinese academies of fine arts, colleges, and universities. Training classes taught by Meximov and Klinduhov at fine arts academies have been Mecca to aspiring young Chinese artists and have a profound influence on China's fine arts education. Renowned artists, including Jin Shangyi and Zhan Jianjun, have studied in such classes. Quan Shanshi and other influential artists have also studies at Repin Academy of Fine Arts in Leningrad, the former Soviet Union. Hence, the Soviet Teaching Model has been integrated into college fine arts education in the early days of the People's Republic of China.
Although internationalization and the popularity of the Internet in the 1980s ushered in an era of diversification in college fine arts education in China, the Soviet Model still held sway more or less. As a result, it seems quite natural that realistic painting still occupies an authoritative position in China's college fine arts education.

\section{B. Overlooking Students' Creativity and Awareness of Innovation}

In college fine arts education in China, little attention has been paid to students' creativity as well as their awareness of innovation which is an important principle of art.

The "awareness of innovation" is a prerequisite for artistic life. Everybody is a unique individual. Instead of duplicating others' works, the value and essence of art is to perceive life with one's own experiences and interpret his/her own definition of art. Copycats can only live in the shadow of others. However, the current college fine arts education suffers from collective amnesia due to standardization, oblivious of the exciting moments when one first gets attached to art. Whenever teachers enter the classroom and see students' painting on the wall, they can't help wondering if they are the works of the same person. The transformation of the status quo probably requires the change of the macro environment of college education, in which both teachers and students should strive to seek a breakthrough in terms of the artistic "innovative awareness."

\section{Decline of Overall Quality of Fine Arts Majors in College}

The overall quality of fine arts majors in college declines due to the popularization of the "elite," which is a result of the expanded enrollment.

China started its large-scale expansion in college enrollment in accordance with The Action Plan for Invigorating Education Oriented Toward the $21^{\text {st }}$ Century, which was issued by the Ministry of Education in 1999. While the Ministry of Education came to realize in 2008 that although the 1999 enrollment expansion action plan had been quite effective in popularizing college education and enhancing citizens' cultural awareness, it is an undeniable fact that the overall quality of college students, who used to be assigned a guaranteed job upon graduation, has been declining during the process of transformation from elite education to mass education.

Due to the uniqueness of fine arts as a major, the requirements on college candidates for the fine arts major are lower than those on non-fine arts major candidates during the 
process of the expanded enrollment. In many parents' eyes, the relatively lower requirements seem like "the only resort" which would save their children from failure in the college entrance examination. Some students with poor academic performance were forced by their parents to study fine arts. Consequently, among a motley crowd of fine arts majors in college, some just lack interest in learning and that has made it difficult for college fine arts teachers to conduct their classes.

\section{Detrimental Effect of Test-oriented Education}

The test-oriented education could stifle "genius" in college education.

It is said that there are two culprits responsible for the stifling of art genius: stick figure painting for children and cram schools intended for candidates to pass the college entrance examination. The criticism may sound extreme, but whoever has been a tutor in such a cram school will agree that the teaching model there can both send into college an average student with no foundation in fine arts at all and turn a potential genius of art into a mediocre person. The reason for this strange phenomenon is simply that the marking of college entrance examination papers requires the obliteration of individuality and selects the qualified students by using the same method for the sake of the so-called fairness. Genius painters who have gone down in history such as Van Gogh and Picasso couldn't have passed the Chinese college entrance examination if they had taken it. To pass the college entrance exam, everyone has to be like a smooth pebble with no sharp edges at all.

Therefore, it has become a significant challenge for college fine arts teachers to save "geniuses" from test-oriented education and change college students' mentality which has been developed in the cram school. It is no easy job to teach students to think on their own, restore their childhood interest in painting, and cultivate an independent artistic personality.

However, besides understanding the current situation of college fine arts education in China, the change of the status quo should be made on the basis of grasping the spirit and the current situation of Chinese fine arts.

\section{SPIRIT OF Chinese Fine ARTS AND ConteXt OF CONTEMPORARY FINE ARTS}

\section{A. The Six Methods of Painting Appreciation}

When it comes to Chinese fine arts, one cannot but mention the "six methods." As early as the South Qi Dynasty(479 A.D. - 502 A.D.), the painter and critic Xie He already mentioned in his Comments on Paintings the "six methods" of painting appreciation. Among them, the most important principle was a "vivid artistic appeal", which was the ultimate pursuit of the painter. The invisible and intangible "artistic appeal" was the supreme state of painting and embodied the much valued abstract expression in Chinese culture. Chinese people tend to explore their ego and express their emotions through the art of painting. Therefore, Chinese art is "egotistical", "spiritual", and "poetic."

\section{B. The Spirit of Abstract Expression}

In fact, in traditional Chinese culture, "abstract expression" is a painting language older than "realistic expression." "Abstract painting" and "realistic painting" are juxtaposed terms. As a traditional and unified technique, the latter has more followers whereas the former focuses on the ethereal beauty of painting strokes. Zong Baihua once said, "The strokes in both Chinese calligraphy and Chinese painting tend to dance." The artistic language of "abstract painting" attaches greater importance to the interaction between the painting itself and the painter, which is characteristic of a "vivid artistic appeal." It is a manifestation of the oriental charm deeply rooted in China's unique cultural context.

\section{Model of Contemporary Chinese Fine Arts}

Contemporary Chinese fine arts refer to experimental Chinese fine arts after China's reform and opening to the outside world. Different from realistic painting with distinct ideological features as well as from realistic painting techniques with a traditional classical flavor, contemporary Chinese fine arts mainly include image painting with a local flavor and diversified forms of conceptual arts. Although influenced by Western post-modern art to a large extent, contemporary Chinese fine arts will by no means evolve into a form like Western post-modern art due to the unique characteristics of Chinese culture. If we blindly copy the Western model, contemporary Chinese fine arts will be doomed to failure as they lack vitality, like water without a source.

\section{Taking the Current Situation of Contemporary Chinese Fine Arts into Account}

From the analysis above, we can see that the root of contemporary Chinese fine arts can be traced to China's unique and brilliant culture, which is profound and inexhaustible. With economic internalization, the cultural development of nations has become increasingly open and diversified. In today's strategic cultural patterns, the Western cultural hegemony has become a prominent issue. If a weak culture just follows the trend, it will become disoriented and lose its own identity. As the cradle of artists, academies of fine arts in China should identify their cultural identity according to the national conditions, derive nutrition from traditional Chinese art, and conceive innovative action plans while taking into account the current situation of contemporary Chinese fine arts.

\section{OUTLOOK AND Strategy ANALysis}

College fine arts education in China has its particular course of development. We can learn from Westerners, but we can't copy them blindly. Transformation may be achieved through the following approaches:

\section{A. Cultivating Student's Innovative Awareness}

College fine arts teachers should advocate "innovative awareness" in their teaching and encourage students to value creativity and innovation rather than mere imitation. The master of Chinese painting Qi Baishi once said, "Whoever learns from me will thrive and whoever imitates me will fail", which means only by learning how to learn instead of blindly copying others, can one obtain artistic vitality, otherwise he/she is doomed to failure. The value of art lies in its uniqueness. 
Everybody has his/her unique life experiences and personality. Therefore, students should be taught to take a sincere attitude toward art and be encouraged to "speak the truth." Everyone's artistic expression should be different from others'. The prerequisite for innovation and creativity is to face one's true self.

\section{B. Teaching Students in Accordance with Their Aptitudes}

Teachers should try as much as possible to adopt the "case study" approach instead of the "one size fits all" approach in teaching. "Teaching students in accordance with their aptitudes" is a time-honored principle advocated by Confucius more than 2,000 years ago. This principle is still applicable today, especially in the teaching of fine arts, a field which places a great emphasis on individuality.

First, while college students share some common physical and psychological characteristics, which are usually stable, these characteristics are to some extent changeable and particular. Teachers should not only grasp students' common characteristics at different stages, but also study their individual characteristics. They should take a practical standpoint. That is to say, they should neither make too high requirements upon students who have poor learning competency nor provide shallow and insufficient knowledge for students who have great potentials.

Second, teachers should equip themselves with a discerning eye that easily recognizes different aptitudes of their students: it is unnecessary to stress the importance of line drawing to a student who is good at using colors because he will probably use coloring in the layout of his painting to achieve an equally good effect. Only with a discerning eye, can teachers suit their teaching to the needs of students with different levels and aptitudes and provide guidance for them.

\section{Teaching Students to Think Independently}

According to John Stuart Mill, the well-known British liberalist thinker in the $19^{\text {th }}$ century, it would be a blessing for one's nation if he/she could think on his/her own and take independent action in his age. Therefore, independent thinking is of vital importance to both the country and the whole society.

Teachers should try to develop students' habit of independent thinking and learning so that students can explore further on their artistic journey after class. As the saying goes, it is better to teach one to fish than to give him a fish. The old proverb means " if you give someone a fish, he will soon eat it up; it is better to teach him to fish because in this way he can have fish for a lifetime." Likewise, a teacher should turn their students into artists who can think on their own instead of blind followers who will be at loss if .

\section{Interactive Teaching}

Interactive teaching has been a highly recommended teaching approach in recent years. The procedure is as follows: propose a subject - raise questions about the subject-think about the questions and discuss them-seeking answers to the questions - make a summarization. Teachers should first propose a subject which can be discussed. The purpose of doing so is to activate students' minds, enhance their initiative to learn, develop their good habit of learning autonomously. The core of this teaching approach is "communication" and "dialogue." Teachers must not lecture on what they would like to teach students while ignoring students' individual needs.

Teachers should abandon the old cramming teaching model and foster an interactive teaching atmosphere instead. In such a learning environment, students are encouraged to share and discuss different ideas and make their thoughts mature in this process. In this way, teachers may adjust their teaching approaches and teaching content in time because they can better understand students' needs during the interactive teaching process.

\section{E. Attaching Importance to Indirect Learning}

For majors where techniques play a major role, good indirect learning experience may bring about great progress in painting techniques. If students merely depend on direct learning experience and abandon good indirect learning experience, it will be an enormous waste of valuable resources and students will be misled on a wrong path. Indirect learning can be conducted in the following ways:

First, teachers should do their utmost to provide students with a learning atmosphere and various opportunities to be exposed to top-class fine arts. They should make full use of the online resources to broaden students' horizons, show students as many master painters' works as possible in class. Students should be encouraged to learn directly from worldclass master painters. Many outstanding master painters in China, such Xin Dongwang and Liu Xiaodong, are "faithful fans" of Freud, the world-renowned oil painting master. It is obviously much more beneficial for students to learn from Freud than from his "faithful fans."

Second, teachers should direct students' attention to contemporary fine arts and gallery exhibitions. It is an important indirect learning process to appreciate the original works of master painters because it will give the viewer the truest sensory experiences. It is impossible for innovation and creativity to come out of nothing. One can only see far by standing on the shoulders of a giant. Students may not have grasped exquisite painting techniques, but if they have a very good artistic taste and a discerning eye for artistic appreciation, they will be able to develop learner autonomy and find problems in their works by themselves when teachers are not available.

\section{CONCLUSION}

As the cradle of Chinese artists, college fine arts education should improve itself through reform and integrate itself into society. "The export of Chinese culture" is now a hot topic. As a significant component of Chinese culture, fine arts also serve as an important cultural messenger that delivers the "national image." This honorable mission can only be accomplished based on a clear self-awareness and a sound analysis of reality.

China's college fine arts education must break the routine and seek new paths. It should not deny itself completely or copy others blindly. Nor should it shut itself off from the outside world. China's college fine arts education should reach out to the outside world, find new expression in traditional Chinese culture, demonstrate a strong national flavor, help 
build China's "new image", and seek a more diversified development model. A more brilliant future is awaiting China's college fine arts education!

\section{ACKNOWLEDGMENT}

This paper would not have been completed without the support of the following people:

First, my heartfelt thanks go to my family for their great care and unswerving support during the whole process of my writing this paper. Second, I would like to extend my sincere gratitude to Mr. Lin Bo, a teacher of fine arts from Jinan University for his valuable advice on my paper. My thanks also go to Ms. Su Jing, a teacher of English from Shandong Normal University, who has offered enormous help in translating this paper from Chinese into English. Finally, I am greatly indebted to all my teachers and friends for their encouragement and assistance while I wrote this paper!

\section{REFERENCES}

[1] Shaobin Zhou, College Liberal Arts Education Series. Hangzhou, Zhejiang: Zhejiang University Press, 2006.

[2] Zhenyu Wong, Chinese Art Education Encyclopaedia: Fine Arts Volume. Hangzhou, Zhejiang: Chinese Academy of Fine Arts Press, 2009.

[3] Peng Duan et al, Coursebook for College Fine Arts Undergraduates (Teacher Education). Changsha, Hunan: Hunan Fine Arts Press, 2010.

[4] Ping Gu, Textbook for Fine Arts Majors in Normal Universities. Nanjing, Jiangsu: Jiangsu Fine Arts Press, 2006.

[5] Peirong Huang, Textbook Series for Teacher Education Professional Classroom Teaching Skills Training. Xiamen, Fujian: Xiamen University Press, 2008.

[6] Shaochun Yin, Research on Contemporary Chinese Fine Arts Education, Vol I. Beijing: Capital Normal University, 2013.

[7] Lu Huang, Fine Arts Education Technology. Changsha, Hunan: Hunan Fine Arts Press, 2011.

[8] Lijia Li, Textbook for College Fine Arts Education Professional Practice Ability Development. Chongqing: Southwest University Press, 2011

[9] Daosen Zhang, Chinese Fine Arst Appreciation: College Liberal Arts Education Series . Hangzhou, Zhejiang: Zhejiang University Press, 2005

[10] Shibin Liu and Linhua Cai, New Horizon Series for Fine Arts Teaching Reform. Chongqing: Southwest University Press, 2006.

[11] Guozhong Zhao, What Is Most Needed in Presenting a Teaching Plan. Nanjing, Jiangsu: Nanjing University Press, 2009.

[12] Dagen Wang, Fine Arts Teaching Plan Design. Shanghai: Shanghai People's Fine Arts Press, 2007. 